\title{
The nice dissection newly conceived: Type $B$ is not a benign disease
}

\author{
Martin Czerny, MD, MBA
}

\author{
From the University Heart Center Freiburg Bad Krozingen, Bad Krozingen, Germany. \\ Disclosures: Author has nothing to disclose with regard to commercial support. \\ Received for publication May 23, 2018; revisions received May 23, 2018; accepted for publication May 30, 2018; \\ available ahead of print July 6, 2018. \\ Address for reprints: Martin Czerny, MD, MBA, Faculty of Medicine, Albert Ludwigs University Freiburg, Uni- \\ versity Heart Center Freiburg Bad Krozingen, Südring 15, Bad Krozingen 79189, Germany (E-mail: martin. \\ czerny@universitaets-herzzentrum.de). \\ J Thorac Cardiovasc Surg 2019;157:864-5 \\ $0022-5223 / \$ 36.00$ \\ Copyright (c) 2018 Published by Elsevier Inc. on behalf of The American Association for Thoracic Surgery \\ https://doi.org/10.1016/j.jtcvs.2018.05.109
}

Type $\mathrm{B}$ aortic dissection has always been regarded as the nice dissection in comparison with other patterns-type A or in particular type non-A non-B-with respect to the initially benign course of the disease without the need for urgent or emergency intervention in many cases. As knowledge of the natural course of the disease evolved, however, it became clear that the occurrence of complications-in particular with regard to aorta-related adverse events- was a matter of time and not a matter if at all or if not. This led to the conduct of the INSTEAD (Investigation of Stent Grafts in Aortic Dissection) study, with its XL follow-up finally confirming a survival benefit in patients having undergone prophylactic thoracic endovascular aortic repair with the intention to close the primary entry tear relative to patients receiving the best medical therapy alone. ${ }^{1}$ These results finally affected European Society of Cardiology aortic guidelines to recommend consideration of thoracic endovascular aortic repair in uncomplicated type B aortic dissection as prophylactic therapy. ${ }^{2}$

Knowledge evolved, and several other morphologic parameters, such as location of the primary entry tear, distance of the primary entry tear to the left subclavian artery, retrograde components of propagation, false-lumen thrombosis status, and finally initial false-lumen diameter, were found to be predictors of early (malperfusion, retrograde type A aortic dissection) as well as late (diameter increase) complications warranting treatment sooner or later. ${ }^{3-5}$ Concomitantly, it became clear that the potential for aortic remodeling is greater the shorter the interval is between the acute event and the time of treatment. The advance to chronic nature and thereby increased stiffness of the membrane is a major determinant of success or failure when the intent is to solve the issue by endovascular means.

All the previously mentioned components have to be seen as bricks in the wall of a bigger picture of acute and chronic aortic dissection, irrespective of location of the primary entry tear and irrespective of extent, whether type A, type B,

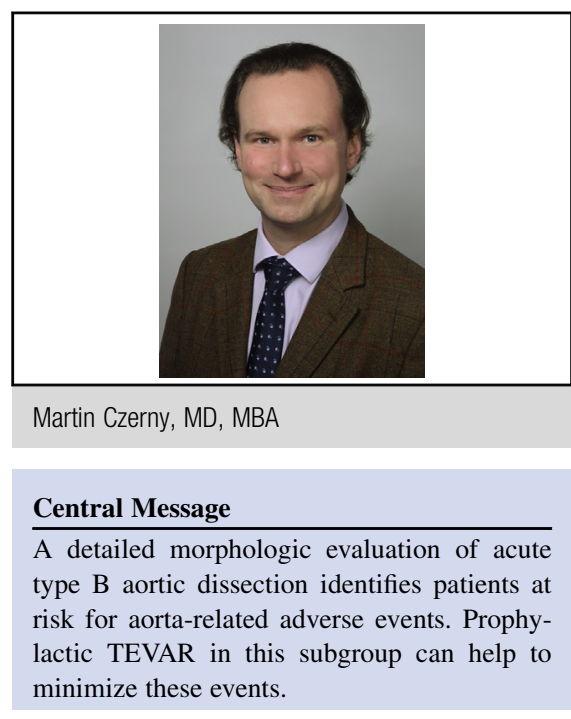

See Article page 854 or-newly developed knowledge closing the gap between the classic A and B terms-type non-A non-B. ${ }^{6}$ This is where the value of the study in this issue of the Journal by Shimamoto and colleagues ${ }^{7}$ has to be seen, namely in the confirmation and support of recently developed knowledge that complications in as yet uncomplicated type B aortic dissections can be foreseen if attention is paid to detail when evaluating morphology.

\section{References}

1. Nienaber CA, Kische S, Rousseau H, Eggebrecht H, Rehders TC, Kundt G, et al; INSTEAD-XL trial. Endovascular repair of type B aortic dissection: long-term results of the randomized investigation of stent grafts in aortic dissection trial. Circ Cardiovasc Interv. 2013;6:407-16.

2. Erbel R, Aboyans V, Boileau C, Bossone E, Bartolomeo RD, Eggebrecht H, et al; ESC committee for practice guidelines. 2014 ESC guidelines on the diagnosis and treatment of aortic diseases: document covering acute and chronic aortic diseases of the thoracic and abdominal aorta of the adult. The task force for the diagnosis and treatment of aortic diseases of the European Society of Cardiology (ESC). Eur Heart J. 2014;35:2873-926. Erratum in: Eur Heart J. 2015;36:2779.

3. Loewe C, Czerny M, Sodeck GH, Ta J, Schoder M, Funovics M, et al. A new mechanism by which an acute type B aortic dissection is primarily complicated, becomes complicated, or remains uncomplicated. Ann Thorac Surg. 2012;93: $1215-22$.

4. Song JM, Kim SD, Kim JH, Kim MJ, Kang DH, Seo JB, et al. Long-term predictors of descending aorta aneurysmal change in patients with aortic dissection. JAm Coll Cardiol. 2007;50:799-804.

5. Tsai TT, Evangelista A, Nienaber CA, Myrmel T, Meinhardt G, Cooper JV, et al. International registry of acute aortic dissection. Partial thrombosis of the false lumen in patients with acute type B aortic dissection. N Engl J Med. 2007;357: 349-59. 
6. Rylski B, Pérez M, Beyersdorf F, Reser D, Kari FA, Siepe M, et al. Acute non-A non-B aortic dissection: incidence, treatment and outcome. Eur J Cardiothorac Surg. 2017;52:1111-7.
7. Shimamoto T, Komiya T, Tsuneyoshi H. Fate of uncomplicated acute type B aortic dissection and impact of concurrent aortic dilatation on remote aortic events. J Thorac Cardiovasc Surg. 2019;157:854-63. 